\title{
Radiological and functional comparison of single-bundle anterior cruciate ligament reconstruction: transtibial versus anteromedial technique
}

\author{
Mustafa ÖZER ${ }^{1}{ }_{\star}$, Hamza ÖZER $^{2}$, Hakan Y. SELEK ${ }^{2}$, Y. Gül BALTACI ${ }^{3}$, Gülcan HARPUT ${ }^{3}$, Anıl TAŞKESEN $^{4}$, Mehmet ÇETINNKAYA $^{5}$ \\ ${ }^{1}$ Department of Orthopedics and Traumatology, Meram Faculty of Medicine, Necmettin Erbakan University, Konya, Turkey \\ ${ }^{2}$ Department of Orthopedics and Traumatology, Faculty of Medicine, Gazi University, Ankara, Turkey \\ ${ }^{3}$ Department of Physiotherapy and Rehabilitation, Faculty of Health Sciences, Hacettepe University, Ankara, Turkey \\ ${ }^{4}$ Department of Orthopedics and Traumatology, Mersin State Hospital, Mersin, Turkey \\ ${ }^{5}$ Department of Orthopedics and Traumatology, Mengücek Gazi Training and Research Hospital, Erzincan University, Erzincan, Turkey
}

Received: 20.02.2017 • Accepted/Published Online: 11.11.2017 • Final Version: 14.06.2018

Background/aim: This study aimed to compare radiological and functional outcomes of patients who had single-bundle anterior cruciate ligament (ACL) reconstruction with autologous hamstring tendon grafts using transtibial (TT) versus anteromedial (AM) femoral tunnel drilling techniques.

Materials and methods: Sixty patients who had been operated on between 2010 and 2013 were enrolled in this study. Tunnel positions and widenings in the femur and tibia were evaluated with radiographs, arthrometric measurements with a Rolimeter arthrometer (Aircast, Summit, NJ, USA), stability assessment with Lachman and reverse pivot shift tests, and functional assessment with the International Knee Documentation Committee and Tegner and Lysholm scoring systems.

Results: Tunnel enlargement in the sagittal and coronal planes of the femur was higher with the TT technique $(\mathrm{P}<0.0001)$ and that of the coronal planes of the tibia was also higher with the TT technique $(\mathrm{P}=0.01)$. During the assessment with the Rolimeter, the difference between sides was significant with the TT technique $(\mathrm{P}=0.013)$. Positive results of the Lachman and reverse pivot shift tests were more frequent with the TT technique $(\mathrm{P}<0.05)$, and the Lysholm scores were higher with the AM technique $(\mathrm{P}=0.001)$.

Conclusion: ACL reconstruction with hamstring autografts by either TT or AM technique demonstrated similar and excellent results in terms of functional outcomes at the end of the first postoperative year. The TT group had increased tunnel enlargement, which may have uncertain long-term outcomes, compared with the AM group.

Key words: Knee, anterior cruciate ligament, arthroscopy, transtibial technique, anteromedial technique

\section{Introduction}

Since anterior cruciate ligament (ACL) reconstruction procedures are increasing worldwide, it is vital to assess which methods of reconstruction are most likely to yield the best long-term functional outcomes. Single-bundle ACL reconstruction using a transtibial (TT) approach is the most traditional and popular technique used by orthopedic surgeons $(1,2)$. However, given that the femoral drilling is done through the initially constituted tibial tunnel, not through an independent medial portal, nonanatomically positioned femoral tunnels are seen more frequently with the TT technique.

Radiological tunnel expansion after ACL reconstruction has been reported in a number of studies (1-4). Although various factors have been blamed in the literature, the etiology of this condition has not

\footnotetext{
*Correspondence: mozer208@yahoo.com
}

been fully clarified yet. These factors include tunnel position, abnormal graft movement inside the tunnel, inflammation caused by excess bony fragments, ethylene oxide remnants, and antigenic reaction with freshfrozen allografts (4-6). During an ACL reconstruction, tunnels in the TT technique are more perpendicular to the axial plane of the femur and tibia than those in the anteromedial (AM) technique (7). AM drilling of the femoral tunnel is performed independently from the tibial tunnel, which enables a more horizontal positioning of the femoral tunnel (8). After the TT approach, mechanical alignment between the femur and tibia may not be built up, and inserted graft material may create mechanical disadvantages in the femur and tibia (9). Unsatisfactory results have been presented in some reports (10-12). In this study, we used functional evaluation methods to 
compare tunnel diameter expansion measurements after ligament reconstruction with the TT and AM techniques among patients diagnosed with ACL tears.

The purpose of this study was to compare radiological and functional outcomes of patients who had single-bundle ACL reconstruction with autologous hamstring tendon grafts using the TT technique versus the AM technique. We hypothesized that cases with tunnel placement closer to the anatomic position would lead to more stability, higher functional scores, and less tunnel enlargement.

\section{Materials and methods}

This study was designed as a nonrandomized prospective trial. A total of 67 patients were enrolled according to the following inclusion criteria: 1) ACL reconstruction with a single-bundle hamstring autograft, 2) no additional ligament injury, 3) no meniscal injury, 4) no history of contralateral knee injury, 5) age between 16 and 45 years, and 6) no history of systemic disease. The initial 33 sequential patients meeting the criteria with ACL rupture were operated on by TT technique (Group A) between 2008 and 2010, and 34 by AM technique (Group B) from 2010 to 2013. Seven patients did not complete the follow-up assessments. Thirty patients in each group completed the follow-up period. All procedures were performed using the arthroscopic technique by the same physician group. Ipsilateral hamstring tendons (musculus semitendinosus and gracilis) were used as sources of grafts. The demographic characteristics of our patients are summarized in Table 1. Institutional review board approval was provided for the study.

\subsection{Surgical technique}

Upon confirmation of the diagnosis of ACL rupture through standard knee arthroscopy portals, the presence of additional intraarticular pathologies was assessed. The ipsilateral hamstring tendons were harvested and converted into quadruple groups. Femoral and tibial tunnels were constituted suitably with the footprints of ACL on the lateral femoral condyle and tibial plateau in the AM technique. In the TT technique, tibial tunnels were modified to be able to constitute femoral tunnels starting from the nearest point to the footprint of the ACL on the lateral femoral condyle (13). In Group A, Transfix (Arthrex,
Naples, FL, USA) was used to perform graft fixation in the femoral tunnel opened through the tibial tunnel (Figure 1). In Group B, the femoral tunnel was prepared by using a low anteromedial portal, and graft fixation was performed with an incision on the lateral aspect of the distal femur using 5.0 Ethibond sutures bound to a $6.5-\mathrm{mm} \mathrm{AO}$ screw ( DePuy Synthes, West Chester, PA, USA) placed in a $30^{\circ}$ proximally directed position, as seen in Figure 2, thus tightening the loose Ethibond suture attached to the graft as the screw advanced into the femur. In the tibial aspect, sequential fixation was performed with an interference screw in the tunnel and staple on the cortex in both the TT and AM techniques (Figure 2).

\subsection{Rehabilitation}

Weight-bearing of patients was allowed on their operated site from the first day of operation onwards as long as they could tolerate the pain. During the first 6 weeks knee flexion to $90^{\circ}$ and after 12 weeks knee flexion at $120^{\circ}$ or more was permitted. During the first 3 months, an adjustable hinged knee brace was used. After 8 months, patients were permitted to return to any sports activities that they were participating in before injury after a thorough physical examination and assessment.

\subsection{Evaluation}

For radiological evaluation, anteroposterior and lateral knee radiographs were obtained with patients standing on their feet at the 12th month of follow-up to visualize tunnel locations and measure the expansion of tunnel diameters with digital calipers. The expansion of tunnels was determined in percentage based on the tunnel diameters constituted during the surgery. At control visits, anteroposterior and rotational stabilities were assessed with Lachman and reverse pivot-shift (rPS) tests. For anteroposterior stability comparison between operated and contralateral sides, Rolimeter arthrometer measurements were performed. Lysholm, International Knee Documentation Committee (IKDC), and Tegner activity scores were calculated for functional assessment.

\subsection{Statistical analysis}

All statistical analyses were performed with SPSS 20.0 (IBM Corp., Armonk, NY, USA). P < 0.05 was accepted to be significant. For distribution analysis, the Kolmogorov-

Table 1. Demographic characteristics of patients.

\begin{tabular}{|l|l|l|l|l|}
\hline & $\begin{array}{l}\text { Sex } \\
\text { M / F }\end{array}$ & $\begin{array}{l}\text { Side } \\
\text { R / L }\end{array}$ & Age & Sports injury \\
\hline $\begin{array}{l}\text { Transtibial } \\
(\mathrm{n}=30)\end{array}$ & $30 / 0$ & $19 / 11$ & $\begin{array}{l}28.17 \pm 5.61 \\
(19-40)\end{array}$ & $25(83.3 \%)$ \\
\hline $\begin{array}{l}\text { Anteromedial } \\
(\mathrm{n}=30)\end{array}$ & $28 / 2$ & $18 / 12$ & $\begin{array}{l}28.07 \pm 7.42 \\
(18-44)\end{array}$ & $28(93.3 \%)$ \\
\hline
\end{tabular}




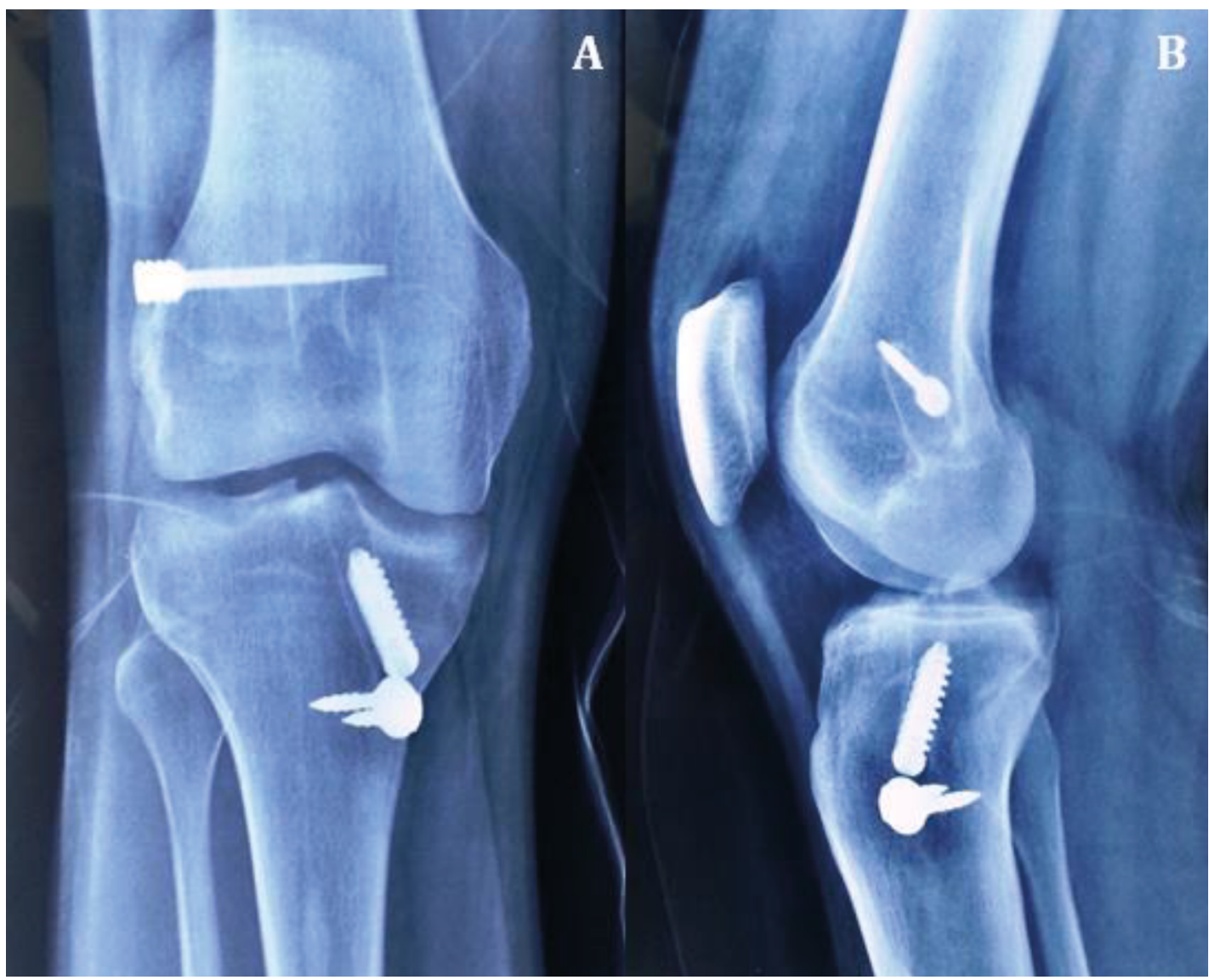

Figure 1. TT technique: follow-up (A) anteroposterior and (B) lateral radiographs.

Smirnov test was used. Paired samples t-tests were used for evaluation of Lysholm-IKDC-Tegner activity scores before and after the operation. The Fischer exact test was used to assess Lachman results, rPS results, and tunnel positions radiologically.

\section{Results}

When we evaluated tibial tunnel positions with lateral radiographs (according to the Amis Jakob line (14)), the anteroposterior diameter of the tibial tunnel in Group A was $45.32 \pm 3.45 \%$ while it was $37.76 \pm 5.0 \%$ in Group B. The tibial tunnel was more anteriorly placed in Group B while it was more posteriorly placed in Group A. There was no significant difference between Group A and Group $B$ in terms of tibial tunnel expansion in the sagittal plane $(P=0.07)$; however, Group A had significantly higher femoral tunnel expansion in the sagittal plane $(\mathrm{P}=0.001)$. When compared, Group A had significantly higher tibial and femoral tunnel expansion in the coronal plane $(\mathrm{P}=$ 0.01 and 0.001 , respectively), as shown in Table 2 .

For the stability tests, arthrometric measurement results with the Rolimeter were $1.15 \pm 0.94$ and $0.65 \pm 0.49$, respectively. When statistical comparison was made, the
Rolimeter value was significantly higher in patients who underwent operation with the TT technique $(\mathrm{P}=0.013)$ (Table 2). During follow-up, Lachman and rPS values were significantly higher in Group A ( $\mathrm{P}=0,001$ and 0.049 , respectively) (Table 2).

For the functional tests, statistical comparisons showed that Group B had significantly higher Lysholm knee scores $(P=0.001)$. In addition, both groups had higher Lysholm knee scores during follow-up compared to preoperative Lysholm scores $(\mathrm{P}=0.001)$ (Table 2). Preoperative IKDC knee evaluation scores showed no significant difference between Groups A and B $(P=0.079)$. Both groups had higher IKDC knee evaluation scores during follow-up when compared to preoperative values $(\mathrm{P}=0.001)$ (Table 2). Statistical comparisons showed no significant difference between groups during follow-up in Tegner activity scores $(\mathrm{P}=0.151)($ Table 2$)$.

\section{Discussion}

It is believed that normal knee kinematics and function can be better restored with anatomical ACL reconstruction. Biomechanical and clinical studies also showed that natural ligament orientation and anatomical 


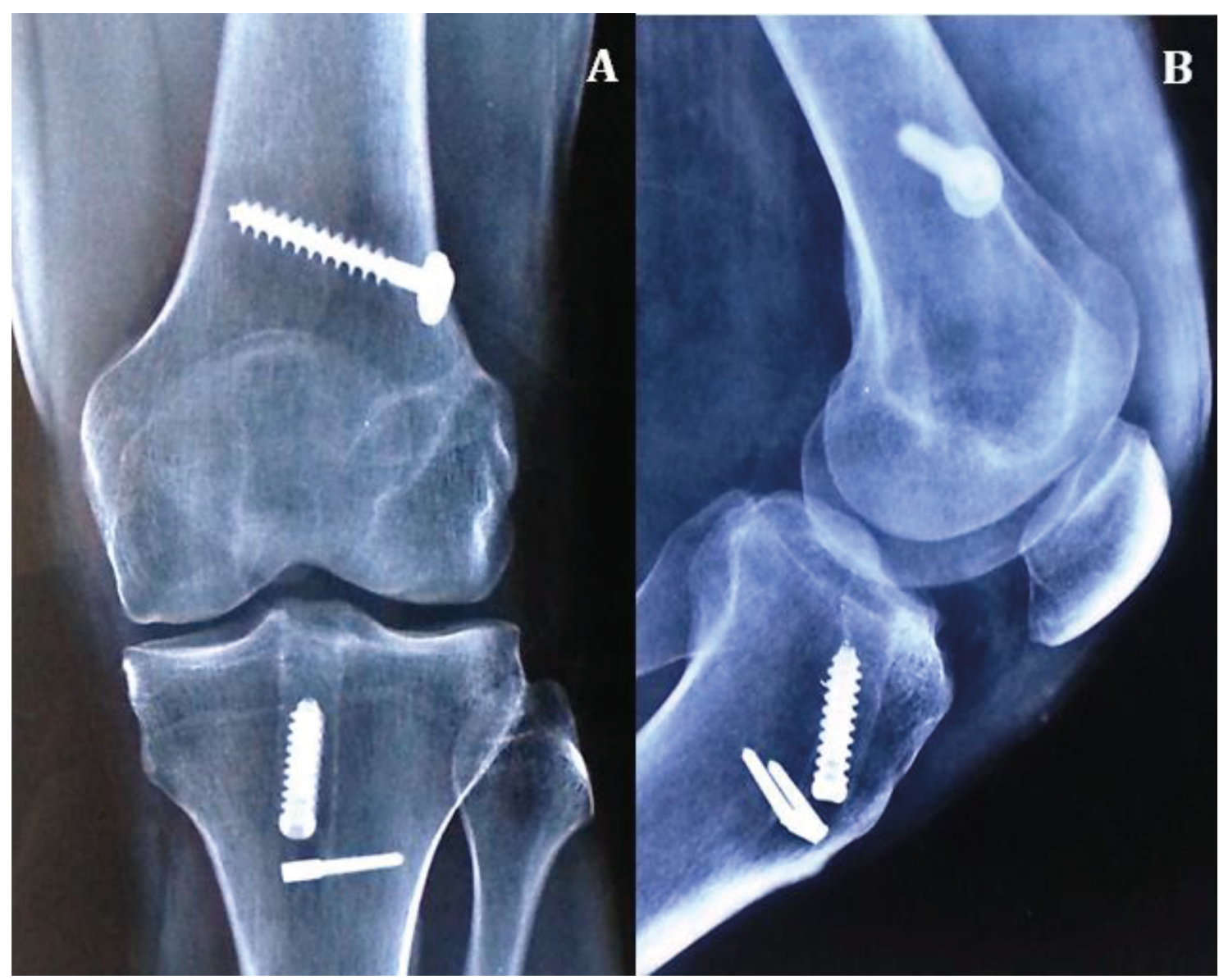

Figure 2. AM technique: follow-up (A) anteroposterior and (B) lateral radiographs.

Table 2. Summary of the results of the study.

\begin{tabular}{|l|l|l|l|l|l|l|l|}
\hline & Rolimeter & $\begin{array}{l}\text { Lachman } \\
(0 /+1 /+2)^{*}\end{array}$ & $\begin{array}{l}\text { Reverse pivot shift } \\
(0 /+1)^{*}\end{array}$ & $\begin{array}{l}\text { Preoperative } \\
\text { Lysholm }\end{array}$ & $\begin{array}{l}\text { Follow-up } \\
\text { Lysholm }^{\&}\end{array}$ & $\begin{array}{l}\text { Preoperative } \\
\text { IKDC }^{\&}\end{array}$ & $\begin{array}{l}\text { Follow-up } \\
\text { IKDC }^{\&}\end{array}$ \\
\hline $\begin{array}{l}\text { Transtibial } \\
(\mathbf{n = 3 0})\end{array}$ & $\begin{array}{l}1.15 \pm 0.94 \\
(0-3)\end{array}$ & $\begin{array}{l}11(36,7) \\
/ 15(50) / 4(13,3)\end{array}$ & $21(70) / 9(30)$ & $\begin{array}{l}65.63 \pm 6.69 \\
(50-80)\end{array}$ & $\begin{array}{l}90.73 \pm 6.40+ \\
(79-100)\end{array}$ & $\begin{array}{l}56.1 \pm 12.3 \\
(35.6-78.2)\end{array}$ & $\begin{array}{l}88.4 \pm 6.8+ \\
(70.1-97.7)\end{array}$ \\
\hline $\begin{array}{l}\text { Anteromedial } \\
(\mathbf{n}=\mathbf{3 0})\end{array}$ & $\begin{array}{l}0.65 \pm 0,49 \\
(0-1.5)\end{array}$ & $\begin{array}{l}24(80) \\
/ 6(20) / 0(0)\end{array}$ & $27(90) / 3(10)$ & $\begin{array}{l}71.47 \pm 9.37 \\
(48-96)\end{array}$ & $\begin{array}{l}96.45 \pm 3.69+ \\
(88-100)\end{array}$ & $\begin{array}{l}59.5 \pm 12.5 \\
(41.4-87.4)\end{array}$ & $\begin{array}{l}91.3 \pm 5.7+ \\
(72.4-98.9)\end{array}$ \\
\hline P-value & $0.013^{*}$ & $\begin{array}{l}0.001^{*} \\
\left(\chi^{2}=14.476\right)\end{array}$ & $\begin{array}{l}0.049^{*} \\
\left(\chi^{2}=3.891\right)\end{array}$ & 0.007 & $<0.0001^{*}$ & 0.288 & 0.079 \\
\hline
\end{tabular}

\begin{tabular}{|l|l|l|l|l|l|l|}
\hline & $\begin{array}{l}\text { Preoperative } \\
\text { Tegner\& }\end{array}$ & $\begin{array}{l}\text { Follow-up } \\
\text { Tegner }\end{array}$ & $\begin{array}{l}\text { Tibial tunnel expansion } \\
\text { at sagittal plane }\end{array}$ & $\begin{array}{l}\text { Femoral tunnel expansion } \\
\text { at sagittal plane } e^{\&}\end{array}$ & $\begin{array}{l}\text { Tibial tunnel expansion } \\
\text { at coronal plane }\end{array}$ & $\begin{array}{l}\text { Femoral tunnel expansion } \\
\text { at coronal plane }\end{array}$ \\
\hline $\begin{array}{l}\text { Transtibial } \\
(\mathrm{n}=30)\end{array}$ & $\begin{array}{l}6.80 \pm 0.81 \\
(4-9)\end{array}$ & $\begin{array}{l}5.17 \pm 1.39+ \\
(3-7)\end{array}$ & $\begin{array}{l}44.21 \pm 14.03 \\
(10.60-65.50)\end{array}$ & $\begin{array}{l}71.97 \pm 19.76 \\
(30.50-107.40)\end{array}$ & $\begin{array}{l}45.85 \pm 12.88 \\
(21.30-76.30)\end{array}$ & $\begin{array}{l}59.59 \pm 17.89 \\
(11.10-99.20)\end{array}$ \\
\hline $\begin{array}{l}\text { Anteromedial } \\
(\mathrm{n}=30)\end{array}$ & $\begin{array}{l}6.73 \pm 1.17 \\
(4-9)\end{array}$ & $\begin{array}{l}5.63 \pm 1.07+ \\
(4-7)\end{array}$ & $\begin{array}{l}37.09 \pm 15.73 \\
(13.40-66.60)\end{array}$ & $\begin{array}{l}45.05 \pm 14.87 \\
(13.80-76.60)\end{array}$ & $\begin{array}{l}36.09 \pm 15.58 \\
(11.0-62.80)\end{array}$ & $\begin{array}{l}43.31 \pm 15.43 \\
(15.10-72.20)\end{array}$ \\
\hline P-value & 0.798 & 0.151 & 0.070 & $<0.0001^{*}$ & $0.01^{*}$ & $<0.0001^{*}$ \\
\hline
\end{tabular}

${ }^{*}: \mathrm{P}<0.05$ (between two methods). ${ }^{\&}:$ Mean $\pm \mathrm{SD}$ (minimum-maximum). $+: \mathrm{P}<0.05$ (as compared to preoperative values in each group). ${ }^{*}: \mathrm{n}(\%)$. 
restoration can help in obtaining natural knee kinematics and stability (15-19). With the traditional TT technique for ACL reconstruction, the tibial tunnel is placed more posteriorly than its anatomical position, and the femoral tunnel is placed more superiorly and anteriorly. The success rate of single-band ACL reconstruction in the literature is between $69 \%$ and $95 \%(9,18)$. The reason for unsuccessful cases seems to be nonanatomical placement of the graft. If ACL reconstruction is not done considering the anatomical points, residual rotational instability may remain in spite of the restoration of the anterior-posterior stability (5). Femoral tunnels in more oblique orientations would better control excessive tibial rotation, which is the most common problem seen after ACL reconstruction (12).

Anatomically placed tibial and femoral tunnels have obtained a consensus in the literature for providing the preferred results, but techniques to achieve this goal are highly debated. Some laboratory and clinical studies showed the biomechanical superiority of ACL reconstruction with anatomical femoral tunnel positioning $(6,7,11,14)$. Moreover, some researchers stated that femoral tunnel obliquity and restoration of the ACL footprint on the femoral side could be obtained as in the AM technique with the TT technique (15). In most biomechanical studies, minimal alterations in femoral tunnel position led to significant changes in postoperative graft isometry and knee stability $(17,18)$. Experienced surgeons can open the femoral tunnel into the ACL attachment site using the TT technique, but the position of the tibial tunnel would be more posterior, which leads to a more perpendicular graft position and at least $15^{\circ}$ of graft deviation from the mean sagittal tunnel obliquity (19). It was previously recommended that in order to prevent compression owing to the vertical graft alignment in the TT technique, the tibial tunnel should be opened more posteriorly (19). However, in comparison with the femoral tunnel, nonanatomic positioning of the tibial tunnel does not affect the stability. Studies have shown that not only the femoral tunnel and the localization of the tibial tunnel are important for the rotational stability of the knee, and anatomically correct positioning of the tibial tunnel has been reported to support knee joint kinematics (20). Just as Purnell et al. (13) described, we endeavored to set the posterior border of outlet openings of tibial tunnels on the tibial plateau as the ridge between the medial and lateral tibial eminences. However, we felt obliged to concede this anatomic location for the sake of proper femoral tunnel drilling.

In previous studies, preparation of femoral tunnels through the tibial tunnels might have caused expansion of tibial tunnels (13-16). In our study, a statistically significant difference in tibial tunnels was detected in
Group A. Moreover, Group A had a statistically significant difference also in the femoral side. The AM technique enabled the formation of a more horizontal femoral tunnel when compared with the TT technique, and in the former one, applied forces to the tunnel walls by graft material were higher, which increased expansion.

In our study, we compared and evaluated tibial translation and rotational stability by Lachman test, Rolimeter arthrometer, and rPS tests. Patients who were operated on using the TT technique had significantly higher values for all three parameters. We think that this loss of stability is due to posterior displacement of the tibial tunnel while trying to obtain appropriate femoral tunnel positioning and thus losing the oblique alignment of the graft, which later prevents obtaining appropriate knee kinematics caused by vertical graft placement. In the literature, it is emphasized that knee stability kinematics were contributed by not only the tunnel placement but also by the fixation technique and size of grafts (21). Since anatomically placed grafts mimic the native ACL better, natural knee kinematics are better supplied and degeneration risk decreases. In a study by Abebe et al., grafts placed vertically in the sagittal plane needed more power to endure anterior forces (22). In our study, patients who were operated on using the TT technique were more unstable. Albeit with clinical insignificance, the AM technique was more stable, and normal knee kinematics with the TT technique could not be reliably obtained, which might be due to the application of more vertical grafts. Reconstructions with insufficient stabilities and normal knee kinematics increase the longterm risk of osteoarthritis and are associated with a higher risk of insufficiency (22). Anteroposterior and rotational stabilities were superior in our patients operated on with the AM technique. Patients operated on with the TT technique had significantly higher Rolimeter and $\mathrm{rPS}$ values $(\mathrm{P}=0.013$ and $\mathrm{P}=0.049$, respectively) (Table 2$)$. Similar results showing more rotational stability and less laxity with the AM technique were reported in the literature $(10,12,23)$.

Femoral and tibial tunnels opened during ACL reconstruction expand gradually starting in the early postoperative period. Discussion regarding tunnel expansion began in the early 1990s and has increased since then (24). Most of the recent studies failed to demonstrate a correlation between tunnel expansion and clinical results $(25,26)$. Many studies have documented that tunnel enlargement is an early phenomenon occurring within 3 months after ACL reconstruction (1). Some researchers believe that tunnel expansion is an early manifestation of graft failure (26). However, exerted forces from different angles might be an important factor in bony tunnel expansion. It is thought that the magnitude of these forces is related to the graft tunnel angle and intraligamentous tension (25). In this study, we could find no correlation 
between tunnel expansions in the coronal and sagittal planes or between Rolimeter values and functional scores (Lysholm, IKDC, Tegner). Tunnel expansion constitutes a problem in revision cases because of difficulties in finding new tunnels (27). Therefore, decreasing tunnel expansion would be helpful. In our study, patients operated on using the AM technique and having femoral tunnels opened independently from tibial tunnels via targeting the ACL footprint with an anatomical technique had significantly less femoral tunnel expansion in both the coronal and sagittal planes as compared with patients operated on using the TT technique, where the femoral tunnel is dependent on the tibial tunnel via targeting the natural ACL footprint with an anatomical technique. Different techniques for fixation of the graft within the femoral tunnel may affect the femoral tunnel expansion. On the other hand, with the TT technique, femoral tunnel expansion is expected to be less than that with the AM technique, thanks to the stability of the graft both longitudinally and in the transverse plane by virtue of intratunnel fixation rather than the extratunnel fixation used in the AM technique. According to follow-up results, we could not demonstrate

\section{References}

1. Höher J, Moller HD, Fu FH. Bone tunnel enlargement after anterior cruciate ligament reconstruction: fact or fiction? Knee Surg Sports Traumatol Arthrosc 1998; 6: 231-240.

2. Koutras G, Papadopoulos P, Terzidis IP, Gigis I, Pappas E. Short-term functional and clinical outcomes after ACL reconstruction with hamstrings autograft: transtibial versus anteromedial portal technique. Knee Surg Sports Traumatol Arthrosc 2013; 21: 1904-1909.

3. Acar HI, Comert A, Özer H, Tekdemir I, Loukas M, Tubbs RS, Elhan A. Femoral seating position of endobutton in single incision anterior cruciate ligament reconstruction: an anatomical study. Surg Radiol Anat 2008; 30: 630-643.

4. Jansson KA, Harilainen A, Sandelin J, Karjalainen PT, Aronen $\mathrm{HJ}$, Tailroth K. Bone tunnel enlargement after anterior cruciate ligament reconstruction with the hamstring autograft and endobutton fixation technique. A clinical, radiographic and magnetic resonance imaging study with 2 years follow-up. Knee Surg Sports Traumatol Arthrosc 1998; 7: 290-295.

5. Berg EE, Pollard ME, Kang Q. Interarticular bone healing. Arthroscopy 2001; 17: 189-195.

6. L'Insalata JC, Klatt B, Fu FH, Harner CD. Tunnel expansion following anterior cruciate ligament reconstruction: a comparison of hamstring and patellar tendon autografts. Knee Surg Sports Traumatol Arthrosc 1997; 5: 234-238.

7. Arnold MP, Kooloos J, vanKampen. A single incision technique misses the anatomical femoral anterior cruciate ligament insertion: a cadaver study. Knee Surg Sports Traumatol Arthrosc 2001; 9: 194-199. a relationship between tunnel expansion and functional results; however, we think that long-term functional scores would decrease with instabilities caused by tunnel expansion and nonanatomic reconstruction.

There were some limitations of this study. The number of patients in each group was small. The follow-up period was short. CT or MRI was not used for measurement of tunnel enlargement, and we did not determine interobserver variation in the evaluation of radiographs. Another limitation was the difference in the modality of graft fixation to the femoral tunnel.

In conclusion, ACL reconstruction performed with hamstring autografts with either the TT or the AM technique demonstrated similar and excellent results in terms of functional outcomes. Radiographic findings demonstrated some increased bone tunnel enlargement in the TT group, which may have an uncertain long-term outcome compared to the AM group. Vertically placed grafts prevent anterior tibial translation, but rotational stability could not be achieved. This rotational instability may be a reason for graft failure and development of degeneration in the long term.

8. Ahn JH, Jeong HJ, Ko CS, Ko TS, Kim JH. Three-dimensional reconstruction computed tomography evaluation of tunnel location during single-bundle anterior cruciate ligament reconstruction: a comparison of transtibial and 2-incision tibial tunnel-independent techniques. Clin Orthop 2013; 5: 26-35.

9. Scanlan SF, Donahue JP, Andriacci TP. The in vivo relationship between anterior neutral position and loss of knee extension after transtibial ACL reconstruction. Knee Surg Sports Traumatol Arthrosc 2014; 21: 74-79.

10. Franceschi F, Papalia R, Rizello G, Del Buono A, Mafulli N, Denaro V. Anteromedial portal versus transtibial drilling technique in anterior cruciate ligament reconstruction: any clinical relevance? A retrospective comparative study. Arthroscopy 2013; 29: 1330-1337.

11. Alentorn-Geli E, Samitier G, Alvarez P, Steinbacher G, Cugat R. Anteromedial portal versus transtibial drilling techniques in ACL reconstruction: a blinded cross-sectional study at two- to five-year old follow up. Int Orthop 2010; 34: 747-754.

12. Hussein M, van Eck CF, Cretnik A, Dinevski D, Fu FH. Prospective randomized clinical evaluation of conventional single-bundle, anatomic single-bundle and anatomic doublebundle anterior cruciate ligament reconstruction: 281 cases with 3- to 5-year old follow-up. Am J Sports Med 2012; 40: 512-520.

13. Purnell ML, Larson AI, Clancy W. Anterior cruciate ligament insertions on the tibia and femur and their relationships to critical bony landmarks using high-resolution volumerendering computed tomography. Am J Sports Med 2008; 36: 2083-2090. 
14. Amis AA, Jakop RP. Anterior cruciate ligament graft positioning, tensioning and twisting. Knee Surg Sports Traumatol Arthrosc 1998; 6: 2-12.

15. Inderhaug E, Strand T, Fischer-Bredenbeck C, Solheim E. Effect of a too posterior placement of the tibial tunnel on the outcome 10-12 years after anterior cruciate ligament reconstruction using the 70 degree tibial guide. Knee Surg Sports Traumatol Arthrosc 2014; 22: 1182-1189.

16. Loh JC, Fukuda Y, Tsuda E, Steadman RJ, Fu FH, Woo SL. Knee stability and graft function following anterior cruciate ligament reconstruction: comparison between 11 o'clock and 10 o'clock femoral tunnel placement. Arthroscopy 2013; 19: 297-304.

17. Yamamoto Y, Hsu WH, Woo SL, Van Scyoc AH, Takakura Y, Debski RE. Knee stability and graft function after anterior cruciate ligament reconstruction: a comparison of a lateral and an anatomical femoral tunnel placement. Am J Sports Med 2004; 32: 1825-1832.

18. Kopf S, Forsythe B, Wong AK, Tashman S, Irrgang JJ, Fu FH. Transtibial ACL reconstruction technique fails to position drill tunnels anatomically in vivo 3D CT study. Knee Surg Sports Traumatol Arthrosc 2012; 20: 2200-2207.

19. Wang H, Fleischli JE, Hutchinson ID, Zeng N. Knee moment and shear force are correlated with femoral tunnel orientation after single bundle anterior cruciate ligament reconstruction. Am J Sports Med 2014; 42: 2377-2385.

20. Lee MC, Seong SC, Lee S, Chang CB, Park YK, Jo H, Kim $\mathrm{CH}$. Vertical femoral tunnel placement results in rotational knee laxity after anterior cruciate ligament reconstruction. Arthroscopy 2007; 23: 771-778.

21. Howell SM, Gittins ME, Gottlieb JE, Traina SM, Zoellner TM. The relationship between the angle of the tibial tunnel in the coronal plane and loss of flexion and anterior laxity. Am J Sports Med 2001; 29: 567-574.
22. Silva A, Sampaio R, Pinto E. ACL reconstruction: comparison between transtibial and anteromedial portal techniques. Knee Surg Sports Traumatol Arthrosc 2012; 20: 896-903.

23. Wagner LR, Thillemann TM, Mehnert F, Pedersen A, Lind M. Increased risk of ACL revision after anteromedial compared with transtibial technique for femoral drill hole placement during ACL reconstruction. Result from the Danish registry of knee ligament reconstruction. Knee Surg Sports Traumatol Arthrosc 2012; 20: 1-3.

24. Freedman KB, D’Amato MJ, Nedeff DD, Kaz A, Bach BR. Arthroscopic anterior cruciate ligament reconstruction: a metaanalysis comparing patellar tendon and hamstring tendon autografts. Am J Sports Med 2003; 31: 2-11.

25. Brophy RH, Pearle AD. Single-bundle anterior cruciate ligament reconstruction: a comparison of conventional, central, and horizontal single-bundle virtual graft positions. Am J Sports Med 2009; 37: 1317-1323.

26. Pearle AD, Shannon FJ, Granchi C, Wickiewicz TL, Warren RF. Comparison of 3-dimensional obliquity and anisometric characteristics of anterior cruciate ligament graft positions using surgical navigation. Am J Sports Med 2008; 36: 15341541 .

27. Zampeli F, Ntoulia A, Giotis D, Tsiaras VA, Argyropolou M, Pappas E, Georgoulis AD. Correlation between anterior cruciate ligament graft obliquity and tibial rotation during dynamic pivoting activities in patients with anatomic anterior cruciate ligament reconstruction: an in vivo examination. Arthroscopy 2012; 28: 234-246. 